BARROS, Patrícia Marcondes de. A estética tropicalista através das capas de discos: o design psicodélico de Rogério Duarte. Domínios da Imagem, Londrina, v. 12, n. 23, p. 18-31, jul./dez. 2018.

ISSN 2237-9126

\title{
A ESTÉTICA TROPICALISTA ATRAVÉS DAS CAPAS DE DISCOS: 0 DESIGN PSICODÉLICO DE ROGÉRIO DUARTE
}

\section{THE TROPICALIST AESTHETICS THROUGH THE COVERS OF DISCS: THE PSYCHEDELIC DESIGN OF ROGÉRIO DUARTE}

\author{
Recebido em 29/9/2017 e aprovado em 30/1 1/2018
}

Patrícia Marcondes de Barros

Resumo: $O$ presente artigo tem como objetivo analisar algumas produções do poeta, músico e designer baiano Rogério Duarte (1939-2016), especificamente, as capas de discos que construíram a estética do Movimento Tropicalista. Tal (des)construção política e estética perpassa pela contingência histórica e significação que o movimento teve ao propor o rompimento com paradigmas vigentes. Discutiremos inicialmente acerca do que foi o Movimento Tropicalista e suas principais influências e posteriormente, analisaremos as capas de discos produzidas por Rogério Duarte e outros projetos gráficos que construíram a estética tropicalista, travando interlocuções entre vida, arte e resistência ao estabelecido nas décadas de 60 e 70.

Palavras-chaves: Rogério Duarte. Tropicalismo. Capas de discos.

\begin{abstract}
This article aims to analyze some productions of the Bahian poet, musician and designer Rogério Duarte (1939-2016), specifically, the album covers that built the aesthetics of the Tropicalist Movement. Such political and aesthetic (dis) construction permeates the historical contingency and significance that the movement had in proposing a break with existing paradigms. We will discuss what was the Tropicalist Movement and its main influences and later, we will analyze the covers of discs produced by Rogério Duarte and other graphic projects that built the tropicalist aesthetic, bridging the interlocutions between life, art and resistance to the one established in the 60's and 70's.
\end{abstract}

Keywords: Rogério Duarte. Tropicalismo. Album covers.

\footnotetext{
- Pós-doutoranda no Programa de Pós-Graduação em Letras (UFPEL/PNPD CAPES), na linha de pesquisa: Literatura, cultura e tradução (PNPD/CAPES) e Doutora em História Cultural (UNESP).
} 
BARROS, Patrícia Marcondes de. A estética tropicalista através das capas de discos: o design psicodélico de Rogério Duarte. Domínios da Imagem, Londrina, v. 12, n. 23, p. 18-31, jul./dez. 2018.

ISSN 2237-9126

\section{Introdução}

Artista gráfico, compositor, músico, tradutor e poeta. Rogério Duarte (1939-2016) produziu memoráveis capas de álbuns de discos e cartazes de filmes nas décadas de 60 e 70. A presente pesquisa, ainda em sua fase inicial, tem como objetivo analisar algumas de suas produções, especificamente, as capas de discos que construíram a estética do Movimento Tropicalista. Através de pesquisa qualitativa de cunho documental (entrevistas, obras bibliográficas, capas de discos e projetos gráficos) propomos inicialmente a discussão acerca do que foi o Movimento Tropicalista em termos políticos e estéticos e suas principais influências, desde sua relação com movimentos artísticos anteriores às décadas de 60 e 70, por exemplo, a contracultura norte-americana que eclodiu e reverberou o psicodelismo, o op art, pop art, entre outras. Em um segundo momento, analisamos algumas capas de discos elaboradas por Rogério Duarte e outros projetos gráficos que construíram a estética tropicalista.

Rogério Duarte nasceu no interior da Bahia, em 1939. Depois de completar seus estudos em Salvador, seguiu para o Rio de Janeiro, em 1957, para estudar na Escolinha de Arte do Brasil. Neste momento, assinou projetos de cartazes e publicações da União Nacional dos Estudantes (UNE), através do Centro Popular de Cultura (CPC). Teve também intensa participação na imprensa alternativa, a exemplo do projeto gráfico da revista Kaos (1985) e do jornal Flor do Mal (1971), junto a outros artistas como Jorge Mautner, Luiz Carlos Maciel e Caetano Veloso. Lecionou design no Museu de Arte Moderna do Rio e publicou, em 1965, um artigo considerado um dos marcos da literatura especializada, intitulado: "Notas Sobre o Desenho Industrial", veiculado na revista Civilização Brasileira (DUARTE, 1965). A discussão foi acerca da gênese do design gráfico, apontando as diferenças entre arte e design. 
BARROS, Patrícia Marcondes de. A estética tropicalista através das capas de discos: o design psicodélico de Rogério Duarte. Domínios da Imagem, Londrina, v. 12, n. 23, p. 18-31, jul./dez. 2018.

ISSN 2237-9126

Com seu trabalho de desconstrução estética, visionou rumos inovadores para as artes gráficas no Brasil, nas décadas de 60 e 70 . 0 sentimento da época, embalado pela contracultura norte-americana, era do experimentalismo nas novas formas de ser, sentir e pensar. Assim foram os experimentos artísticos de Rogério Duarte, percebidos através de seu trabalho ímpar na imprensa alternativa, nos cartazes dos filmes do Cinema Novo e nas capas de discos tropicalistas, sempre construindo e demolindo velhos paradigmas.

\section{Rogério "Kaos" Duarte: Tropicalismo e identidade nacional}

[...] A essência do Tropicalismo era um desejo amoroso de modernidade para o Brasil. Era todo um ponto de vista que estava, e continua reprimido e que naquele momento histórico a gente pôde veicular. Foi um momento de êxtase, de criatividade real e que alimentou e alimenta até hoje este país. Foi talvez o movimento mais moderno do Brasil no sentido de que ele era um movimento ligado a uma civilização contemporânea e de massas, sem ranços, sem compromissos ou peias ideológicas com facções de esquerda, ou de direita. Era a própria inteligência brasileira se manifestando, num momento de consciência, de lucidez e de paixão por esse país. Era também um momento em que uma potencialidade brasileira se apresentou. Porque quando eu falo de Tropicalismo, sempre digo que não é um movimento, é a própria arte brasileira. O modernismo já era assim. A vocação do Brasil é essa. Essa é a nossa fala. Essa é nossa identidade. Há visões superficiais disso, mas essa vocação brasileira está aí em tudo: nessa garra, nessa paixão, nessa identidade universal do brasileiro. (DUARTE, 2003, p. 138)

"O Tropicalismo sou eu". Com esta afirmação provocativa, Rogério Duarte coloca-se frente ao movimento do qual foi importante mentor e cuja importância não se traduz apenas pelo seu trabalho de elaboração das capas de discos, panfletos e cartazes. O apelido, Rogério "Caos", surgiu quando ainda participava do CPC da UNE, dado certamente por militantes ortodoxos que o achavam "anarquista", relacionado a movimentos 
BARROS, Patrícia Marcondes de. A estética tropicalista através das capas de discos: o design psicodélico de Rogério Duarte. Domínios da Imagem, Londrina, v. 12, n. 23, p. 18-31, jul./dez. 2018.

ISSN 2237-9126

internacionalistas como a contracultura norte-americana que, na época, era entendida como um movimento subjetivo e exótico, verdadeiro ataque à cultura nacional em momento de grandes embates acerca da questão da construção identitária brasileira.

(...) No CPC meu apelido era Rogério Caos, porque, embora marxista também, via o processo criativo como algo que ultrapassava a razão no sentido dogmático. A estética marxista chamava de lixo burguês as vanguardas, a pintura abstrata, a pop art, a música dodecafônica, com as quais eu tinha contato no Museu de Arte Moderna da Bahia, como estudante de artes plásticas e membro da Escola de Teatro. Além disso, os meus cartazes, por exemplo, se comunicavam mais fortemente com a chamada massa do que com aquela coisa programada. Mas o CPC me recusava como burguês vanguardista (DUARTE, 2003, p. 215).

Duarte passou da política engajada do CPC ao desbunde do Tropicalismo cujo boom se deu principalmente através do III Festival de Música da TV Record (1967), do álbum/manifesto "Tropicália ou Panis et Circensis" (julho de 1968) e do programa televisivo na TV Tupi intitulado "Divino, Maravilhoso"(1969), que "invadiu os cinco mil alto-falantes", parafraseando Caetano, divulgando as novas formas de pensar o Brasil e de marcar resistência não apenas à situação contingente de repressão militar, mas também, universalmente, aos paradigmas que já não respondiam aos anseios do "jovem aquariano"l.

O conteúdo estético e político da "mensagem" proposta pelos tropicalistas e os "meios" que encontravam para tal intento amparavam-se conceitualmente na antropofagia oswaldiana, que através da deglutição cultural (realizada intuitivamente) de diversificada teia de referências culturais (não era uma apropriação ou "deglutição" sistemática e racional de elementos, geradora de uma síntese) postularam uma nova cultura

'Os jovens ganharam nesta época várias denominações: "mutantes", "desbundados", "jovens da Era de Aquarius", entre outras, com acepções de predestinação à transformação e, assim, renovação da sociedade em todos os âmbitos. 
BARROS, Patrícia Marcondes de. A estética tropicalista através das capas de discos: o design psicodélico de Rogério Duarte. Domínios da Imagem, Londrina, v. 12, n. 23, p. 18-31, jul./dez. 2018.

ISSN 2237-9126

brasileira. A partir da antropofagia, os elementos do passado e presente, estrangeiros e nacionais, criaram uma arte brasileira diferente das vertentes nacionalistas de até então.

A relação da Tropicália com o ideário contracultural norte-americano através do movimento hippie mostrou seu potencial político através da crítica comportamental e luta das minorias sociais (negros, mulheres e homossexuais). Seu caráter libertário se deu contra as instituições consideradas, já na época, falidas (escola, família, estado, por exemplo), a militância ortodoxa (surge a chamada "Nova Esquerda"), em suma, aos paradigmas centrais do pensamento ocidental.

A obra de Hélio Oiticica, autor do projeto intitulado Tropicália lque deu nome ao movimento), a linguagem geométrica urbana e visual da Poesia Concreta, o Cinema Novo de Glauber Rocha com o filme Terra em Transe (1967) e o aspecto carnavalizado e antropófago de Oswald de Andrade na obra O Rei da Vela (1937), dirigida no teatro por José Celso Martinez Corrêa, traduziram o "espírito da época", sintetizando aquilo que estava acontecendo no mundo e refletindo-se no Brasil.

[...] O tropicalismo, além de ter atuado seu ufanismo e sem demagogia populista; além de ter incorporado o tom parodístico e bem-humorado, crítico e dessacralizador, de Oswald de Andrade e do legado antropofágico do Modernismo; além de ter transferido a criação poética revolucionária para as letras de música; além de ter antropofagicamente, colocado em confronto o legado anterior da música popular brasileira com a música pop internacional; além disso tudo estava assumindo, nos palcos e nos meios de massa, atitudes e comportamentos (...) linguagens novas, muito mais próximas da agitação juvenil internacional do que qualquer outro movimento, dentro ou fora do Brasil. (BUENO, 1979, p. 25)

O Tropicalismo catalisou as inquietações e impasses da situação pós64, promovendo uma renovação estética que abriu novas possibilidades de se pensar o Brasil. Foi uma fase "colorida e barulhenta" que durou pouco, 
BARROS, Patrícia Marcondes de. A estética tropicalista através das capas de discos: o design psicodélico de Rogério Duarte. Domínios da Imagem, Londrina, v. 12, n. 23, p. 18-31, jul./dez. 2018.

ISSN 2237-9126

demonstrando logo desgastes e sinais de fragilidade frente à estrutura rigidamente constituída pelos militares, sendo os seus principais protagonistas, como Rogério Duarte, presos e exilados.

\section{"De Terra em Transe à Flor do Mal": obras do "poeta do design"}

Apresentaremos de forma geral, algumas obras de Rogério Duarte, especificamente, suas memoráveis capas de discos que constituíram a estética tropicalista. Com o grande desenvolvimento da indústria fonográfica no século XX, os LPs começaram a destacar-se pela qualidade visual da capa que outrora tinha um padrão definido constituído apenas pela imagem do artista e título do disco. Com o decorrer do tempo, a capa começou a ser pensada como um bom investimento para a venda do produto musical. No caso do Tropicalismo, cuja maior visibilidade se deu através da música, as capas de discos foram pensadas como parte fundamental de seu manifesto.

O álbum do cantor e compositor Jorge Mautner produzido em 1974, expressa a relação de Duarte com a contracultura, tanto no aspecto estético quanto na ideia de orientalização do Ocidente. 
BARROS, Patrícia Marcondes de. A estética tropicalista através das capas de discos: o design psicodélico de Rogério Duarte. Domínios da Imagem, Londrina, v. 12, n. 23, p. 18-31, jul./dez. 2018.

ISSN 2237-9126

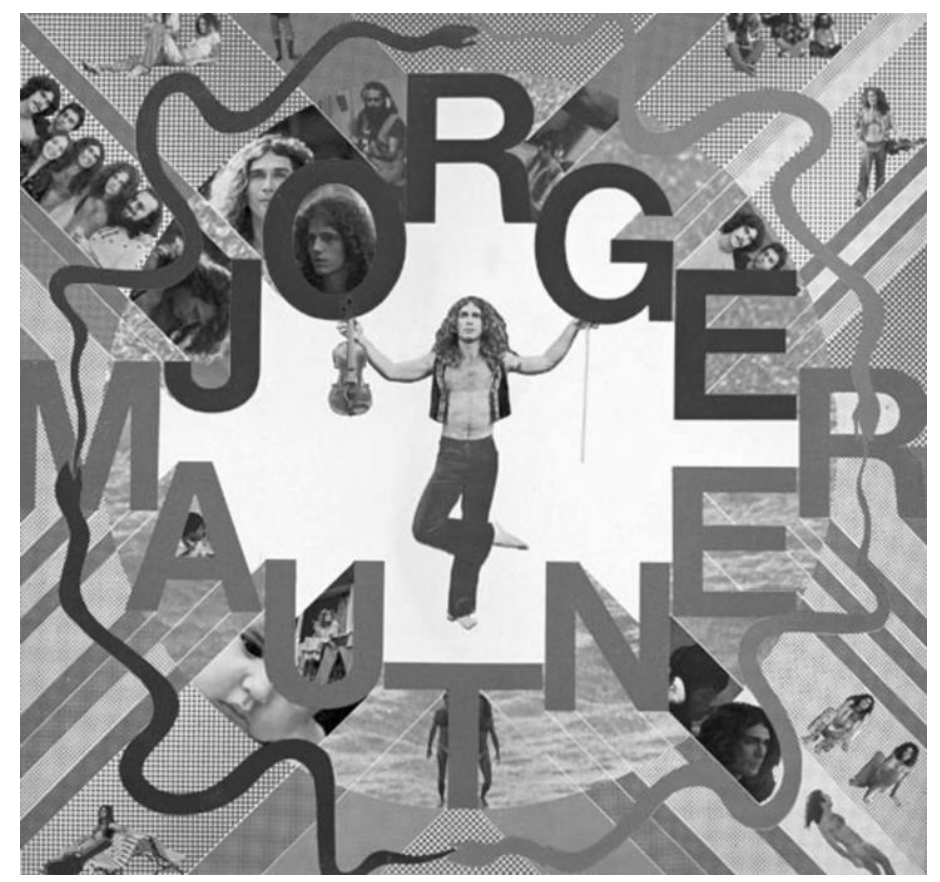

Percebemos, nas capas elaboradas por Rogério Duarte, a influência do psicodelismo, derivado da experiência com as drogas alucinógenas que permitem a intensificação das cores, as deformações e ilusões de ótica, a microvisão detalhista, efeitos parapsicológicos (BARRETO, 1975), entre outros olhares inusitados. Santos (2015, p. 78) faz uma análise da capa do álbum de Jorge Mautner (1974):

[...] A capa é bastante psicodélica, mesclando elementos da cultura hippie com a religiosidade que naquele período estava aflorada em Duarte, as vestes do cantor e as imagens menores comprovam o espírito de busca pela liberdade, as linhas ondulares faz referência a psicodelia do momento. A mistura de cores feita por Duarte se faz presente novamente, nesta obra podemos perceber também uma palheta mais diversificada, os tons não são tão chapados, são mais suaves, o espaço branco no centro também chama atenção, pelo fato de não ser uma característica do artista. A cor branca que no Brasil e em boa parte do mundo é o símbolo da paz, bandeira carregada pelo movimento hippie.

A questão da orientalização do ocidente e a utilização de drogas lisérgicas formaram as bases propulsoras da contracultura nas infinitas 
BARROS, Patrícia Marcondes de. A estética tropicalista através das capas de discos: o design psicodélico de Rogério Duarte. Domínios da Imagem, Londrina, v. 12, n. 23, p. 18-31, jul./dez. 2018.

possibilidades de entendimento da chamada "realidade objetiva". Nas obras de Rogério Duarte fez-se presente, desde 1968, o misticismo religioso, momento em que ele adere à religião Hare Krishna.

Figura 2: Capa do LP Caetano Veloso (1968) produzida por Rogério Duarte.

Disponível em: http://www.brazilcult.com/Ip-caetano-veloso-1968-debut-mutantes-tropicaliapsych-folk-bossa-brasil (Acesso em 23 jul. 2017)

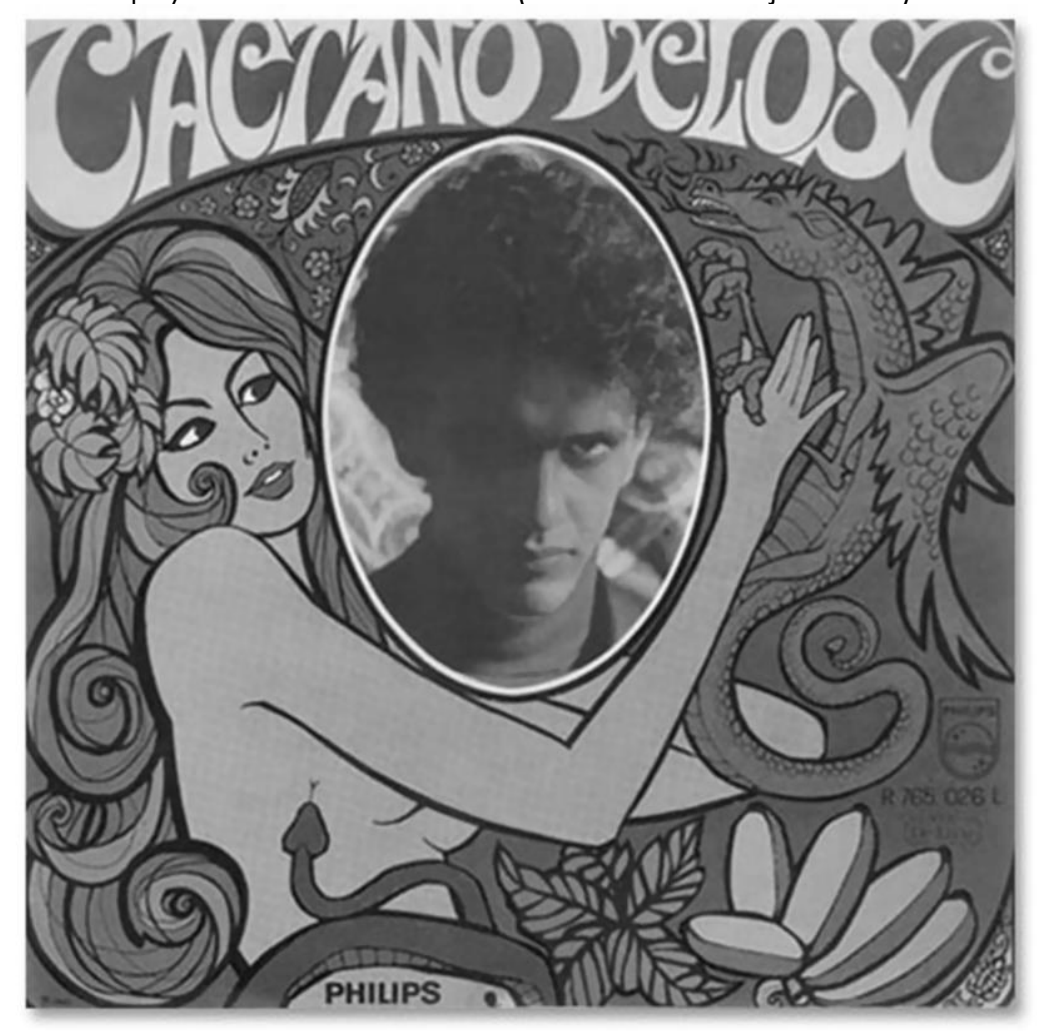


BARROS, Patrícia Marcondes de. A estética tropicalista através das capas de discos: o design psicodélico de Rogério Duarte. Domínios da Imagem, Londrina, v. 12, n. 23, p. 18-31, jul./dez. 2018.

ISSN 2237-9126

A capa do álbum de Caetano Veloso, produzida em 1968, apresenta excesso de elementos visuais, contudo, a centralidade de Caetano não é tirada de evidência². Segundo Jorge Caê Rodrigues (2007):

[...] A ilustração de que Duarte se apropriou para a capa de Caetano guarda em si algo de kitsch, de um surrealismo barato. O contraste entre o arcaico e o moderno que o Tropicalismo expunha também está presente na capa: a composição é convencional - foto do artista no meio, nome em cima, centralizado, mas, por outro lado, os elementos estéticos-formais (tipografia, os fundos cromáticos, elementos pictóricos são fortes, agressivos, exuberantes). No meio de tudo isso, o retrato três por quatro do artista, com um olhar incisivo, estabelece um diálogo com o observador. O jogo do claroescuro da foto torna a face do artista enigmática, enfatiza o aspecto surreal da capa. O verso da capa, em preto-e-branco, repete o nome do cantor no alto do disco e uma moldura com as mesmas características kitsch envolve o texto manuscrito, totalmente livre do grid funcionalista. As capas são uma salada de referências, assim como é a Tropicália. O mundo pop, desenvolvido, psicodélico, atômico, eletrônico era triturado e lançado sobre o país tropical, subdesenvolvido, marginal. A esta multiplicidade Ismail Xavier chama de jogo de contaminação. Tudo isso pode ser visto no design da Tropicália, que rompia com a previsibilidade, abrindo um novo espaço de possibilidade da contemporaneidade. (RODRIGUES, 2006)

Além de figuras mitológicas, como o dragão e a cobra estampada na capa (relacionados ao contexto de repressão ditatorial), outra referência perceptível concerne à antropofagia oswaldiana quanto à natureza exótica e tropical, além das cores vibrantes, sem nenhuma discrição (SANTOS, 2015). A penca de bananas nos remete a Carmem Miranda em sua interpretação de "Yes, nós temos bananas" (1937), representando a brasilidade do próprio projeto tropicalismo. Inevitável também apreciar a capa sem a relacionar com a cultura pop e ao movimento hippie, principalmente com a presença

\footnotetext{
2 SANTOS, Jaqueline Ferreira dos. O LUGAR DE ROGÉRIO DUARTE SOB O SOL DA TROPICÁLIA. Dissertação apresentada ao Programa de Pós- Graduação em Artes Visuais, da Escola de Belas Artes da Universidade Federal da Bahia, Salvador, 2015, p.82.
} 
BARROS, Patrícia Marcondes de. A estética tropicalista através das capas de discos: o design psicodélico de Rogério Duarte. Domínios da Imagem, Londrina, v. 12, n. 23, p. 18-31, jul./dez. 2018.

ISSN 2237-9126

de uma folha que aparentemente é a da canabbis sativa (maconha). A metáfora da liberdade, seu anseio, pode ser verificada em todas as produções de Duarte.

Além das inúmeras capas de discos e cartazes, vale ressaltar sua participação também na imprensa alternativa, denominada de comportamental, marginal, existencial, que veiculava os anseios de parte da juventude imersa na contracultura dos anos 60. Nela, Duarte trabalhou poeticamente textos, desenhos, edição de arte.

O projeto da revista Kaos, por exemplo, vem do movimento do KAOS com K33, pensado por Jorge Mautner, que consistia na subversão e na contestação dos valores vigentes - não apenas políticos, econômicos e sociais, mas, principalmente, morais, psicológicos e existenciais (MACIEL, 1996).

[...]Kaos é o anti cor-de-rosa É Marx + Nietzsche É a chegada do irracional Num mundo economicamente satisfeito No dia da fartura econômica Virá sobre o mundo o grande delírio do sangue e do sexo Surgirá de novo Que nem na Grécia arcaica o ta-tã selvagem das canções de Dionísius-Exu E de outros deuses asiáticos Não haverá deuses, o deus será o próprio homem que se agoniará à procura do grande mistério que restou: a morte. (...) Kaos = conflito criador. Kaos = rebelião constante, postura trágica e dinâmica para a morte Heráclito e Heidegger, os maiores pensadores, que deram ao homem sua terrível dimensão (MAUTNER, 1985, p. 31 e 32).

Fizeram um release da ideia da revista em forma de gravação, comentando, através de um "bate-papo" informal, as principais propostas e mandaram para os jornais e revistas. A ideia não só foi negada por todas estas instâncias, como, também, estereotipada como uma iniciativa hippie, contracultural, associada a uma "maluquice sem propósitos sérios". Maciel,

\footnotetext{
3 Segundo Mautner na obra Fundamento do Kaos (1985), o Caos com "C" significa a dominação e o Caos com "K", a transcendência.
} 
BARROS, Patrícia Marcondes de. A estética tropicalista através das capas de discos: o design psicodélico de Rogério Duarte. Domínios da Imagem, Londrina, v. 12, n. 23, p. 18-31, jul./dez. 2018.

ISSN 2237-9126

um dos editores da revista Kaos, assinala a importância de Rogério Duarte na contracultura, através de sua participação na imprensa alternativa:

[...] O Rogério Duarte é peça fundamental em todas essas produções alternativas, exceto a Rolling Stone. A Rolling Stone era do Lapi, mas Rogério estava na Flor do Mal e no Caos com $K$, inclusive ele fez um projeto gráfico lindo. A gente ia fazer uma revista enorme, do tamanho de um bonde assim, tirado de uma revista europeia. O Rogério tirou, apanhou para a gente a revista que era grandona, bom papel, impressão a cores, um luxo e fez o boneco, o planejamento gráfico e 0 logotipo. Era um Kaos que parecia uma coisa oriental, mas ao mesmo tempo ser um só rabisco. Era muito bonito! Uma coisa mais marcante no projeto do Kaos foi o projeto visual. A ideia do release gravado foi do Mautner junto com o Caetano, conversar sobre o projeto e mandar para os jornais. Não deu em nada, falaram que era coisa de maluco, maconhado...imagina...o Caetano não fuma maconha, era o "Caretano", mas acharam que era maluco. E realmente era maluco. Nós descobrimos isso porque nossa esperança era uma parceria com a livraria Archete francesa, eles editavam coisas aqui. Nós fomos conversar com o diretor da revista responsável no Brasil. Aí nós explicamos o projeto para ele, tava tudo cem por cento!!! Até o momento que a gente entregou o primeiro número... Aí ele disse: Isso é coisa de hippie! Daí não quis fazer... Foi mais um não fazer na minha vida... e na do Rogério também, que é um campeão de não fazer. (BARROS, 2007, p. 236)

Qual o pólen da Flor? "Abra a Flor do Mal: pétalas, corola, insetos maravilhosos, escaravelhos incríveis, beija-flores, algumas fadas voltejantes, serafins, gnomos, sílfides, ogros, ondinas, nereidas, etc" (LUIZ, 1971, p. 8 e 9).

Figura 3: Capa do jornal Flor do Mal (1971)

https://universo70.wordpress.com/category/memoria/

(Acesso em 31/03/2017) 
BARROS, Patrícia Marcondes de. A estética tropicalista através das capas de discos: o design psicodélico de Rogério Duarte. Domínios da Imagem, Londrina, v. 12, n. 23, p. 18-31, jul./dez. 2018.

ISSN 2237-9126

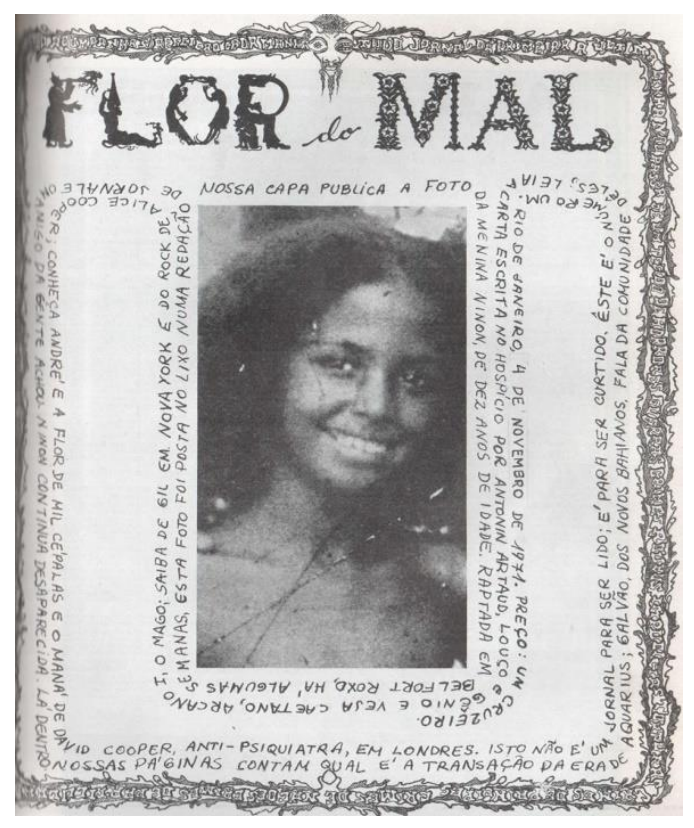

O jornal Flor do Mal, fundado em 1971, com os poetas Tito de Lemos, Torquato Mendonça e Luiz Carlos Maciel, apesar do curto período de circulação, obteve grandes considerações no meio underground brasileiro. Quem escrevia na Flor do Mal eram os próprios Tito de Lemos, Torquato Mendonça, Rogério Duarte e Luiz Carlos Maciel, assim como pessoas que eles conheciam, "antenadas" com as ideias contraculturais, tais como: Antônio Bivar, Joel Macedo, Waly Salomão, José Simão, Antônio Capinam, Célia Maria, Moleque Pereira e amigos da clínica psiquiátrica, que Rogério tinha conhecido quando de sua internação. A redação localizava-se na Rua Clarisse Índio do Brasil, 32, no Rio de Janeiro.

O principal interesse era dar voz aos artistas jovens, de vanguarda, contraculturais, "malucos" que não eram aceitos por nenhum órgão de imprensa. Era intencional a ideia de se fazer uma publicação nada convencional. Rogério Duarte afirmava que os textos tinham que ser escritos à mão e para tanto deveriam contar com uma equipe de calígrafos, como os da Idade Média. A fotografia que ilustra o primeiro número foi encontrada por Torquato Neto no chão da redação do jornal Última Hora, pisoteada. Era a foto de uma menina negra sorrindo, despida do peito para cima, 
BARROS, Patrícia Marcondes de. A estética tropicalista através das capas de discos: o design psicodélico de Rogério Duarte. Domínios da Imagem, Londrina, v. 12, n. 23, p. 18-31, jul./dez. 2018.

ISSN 2237-9126

representando a pureza espiritual que ansiavam. Esta iniciativa durou apenas cinco números, contudo, sua tiragem foi de 40 mil exemplares, dos quais, vendeu-se a metade.

Afora os projetos que não saíram do papel, as conversas que não foram publicadas, mas concretizadas em grandes ideias, encontros e parcerias, sua arte demolidora e antropofágica foi de suma importância para a renovação cultural brasileira.

\section{Considerações Finais}

presente artigo teve como objetivo apresentar o esboço de uma pesquisa (em fase inicial) sobre a estética tropicalista de Rogério Duarte através de suas produções, especificamente, as capas de discos entre outros projetos gráficos. Por meio de pesquisa qualitativa de cunho documental (impressos alternativos, capas de discos, cartazes, entre outros) discutimos inicialmente e de forma geral acerca do que foi o Movimento Tropicalista em termos políticos e estéticos assim como suas principais influências, desde sua relação com movimentos artísticos anteriores às décadas de 60 e 70 por exemplo, o modernismo e o surrealismo, a contracultura norteamericana que eclodiu e reverberou o psicodelismo, o op art, pop art, entre outras. E em um segundo momento, analisamos algumas capas de discos e projetos gráficos tropicalistas produzidos por Rogério Duarte.

Embora o Tropicalismo tenha tido duração efêmera - comumente datado com o início em setembro de 1967 e seu término, em dezembro de 1968 (CONTIER, 2003), suas repercussões alcançam os dias atuais, seja na Arte ou no comportamento através de seu caráter provocador e experimentador, características advindas da contracultura a qual Duarte foi um dos principais protagonistas. Suas obras foram imprescindíveis na constituição de uma contracultura brasileira que ganhou contornos tropicalistas e confluiu para a problematização de um país complexo, 
BARROS, Patrícia Marcondes de. A estética tropicalista através das capas de discos: o design psicodélico de Rogério Duarte. Domínios da Imagem, Londrina, v. 12, n. 23, p. 18-31, jul./dez. 2018.

ISSN 2237-9126

diversificado e com enorme desigualdade social, não oferecendo apenas respostas pontuais, mas lançando diferentes questões, muitas desconcertantes, em relação ao caráter identitário brasileiro, à repressão ditatorial, as formas de resistência à repressão, ao dualismo colocado entre o político e o estético, o popular e o erudito, a arte e o design, a exemplo.

O aspecto de luta e resistência daqueles anos marcaram suas interlocuções com a política, a vida e a arte. O poeta, o designer, o hare krishna, o "tropikaoslista" torturado pela ditadura militar e internado em clínica psiquiátrica coexistem numa só pessoa. Rogério Duarte reflete sobre sua prisão em 1968: "(...) Primeiro, a prisão em 1968, depois o hospício em 70. Foi um processo doloroso do meu novo ser que nascia em metanóia (...) Chego a achar que valeu a pena. Torna-te quem és. Como Nietzsche. 0 êxtase e a pena fazem com que a alma não seja pequena" (DUARTE, 2003, p. 12 e 13).

\section{Referências}

BARRETO, Jorge Lima. Rock/Trip: música pop e droga. Porto: Rés, 1975.

BARROS, Patrícia Marcondes. Provocações brasileiras: a imprensa contracultural Made in Brazil - coluna Underground (1969-1971), Flor do Mal (1971) \& a Rolling Stone brasileira (1972-1973). Tese (Doutorado em História) Universidade Estadual Paulista, Assis. 2007.

BUENO, André Luiz. Contracultura: As utopias em marcha. Dissertação (Mestrado em Letras) - Pontifícia Universidade Católica, Rio de Janeiro. 1979. 
CONTIER, A. D. et al. O Movimento Tropicalista e a Revolução Estética. Caderno de Pós-Graduação em Educação, Arte e História da Cultura, v. 3, n. 1, p. 135-159, 2003.

DUARTE, Rogério. Notas sobre o Desenho Industrial. Revista Civilização Brasileira, Rio de Janeiro, n. 4, p. 227-247, set. 1965.

DUARTE, Rogério. Tropicaos. Rio de Janeiro: Azougue Editorial, 2003.

LUIZ, André. Flor do Mal. 3. ed. Rio de Janeiro: s.e, 1971.

MACIEL, Luiz Carlos. Geração em transe: memórias do tempo do Tropicalismo. Rio de Janeiro: Nova Fronteira, 1996.

MAUTNER, Jorge. Fundamento do Kaos. São Paulo: Ched Editorial, 1985.

RODRIGUES, Jorge C. O Design Tropicalista de Rogério Duarte. In: MELO, Chico H. de. (Org.) O Design Gráfico Brasileiro dos Anos 60. São Paulo: Cosac Naify, 2006.

SANTOS, Jaqueline Ferreira dos. O lugar de Rogério Duarte sob o sol da Tropicália. Dissertação (Mestrado em Artes Visuais) - Universidade Federal da Bahia, Salvador. 2015. 